\title{
Hubungan Implementasi Sistem Resep Elektronik terhadap Kepuasan Pengguna
}

\author{
I Gusti Otty Septya Amanda1, Farid Agushybana², Sudiro³ \\ 1,2,3Fakultas Kesehatan Masyarakat, Magister Administrasi Rumah Sakit, Universitas Diponegoro \\ igustiamanda93@gmail.com ${ }^{1}$, hybana@gmail.com²
}

\author{
ABSTRAK \\ Diajukan 29 November 2019 Diperbaiki 2 Agustus 2020 Diterima 12 Agustus 2020
}

Latar Belakang: Salah satu strategi menurunkan medication error untuk meningkatkan kualitas mutu rumah sakit yaitu mengimplementasikan resep elektronik. Namun dalam penerapannya masih ditemukan kendala terkait interaksi antara teknologi dengan sumber daya manusia, serta pengelolaan dan evaluasi resep elektronik yang belum optimal.

Tujuan: Penelitian ini bertujuan mengetahui hubungan implementasi resep elektronik terhadap kepuasan pengguna.

Metode: Penelitian observasional ini menggunakan metode Partial Least Square (PLS) dalam pengolahan datanya. Besar sampel sebanyak 70 responden yang diambil secara total sampling. Variabel yang digunakan antara lain implementasi resep elektronik, kepuasan pengguna, dukungan manajemen, dan lingkungan kerja.

Hasil: Hasil penelitian menunjukkan variabel dukungan manajemen dan lingkungan kerja berhubungan terhadap implementasi resep elektronik dengan tingkat $\alpha=5 \%$. Serta, variabel implementasi resep elektronik berhubungan terhadap kepuasan pengguna dengan tingkat $\alpha=5 \%$.

Kesimpulan: Implementasi resep elektronik mempunyai pengaruh terhadap kepuasan pengguna. Dengan demikian, evaluasi implementasi resep elektronik telah sesuai dengan harapan dan manfaat yang dirasakan pengguna, namun perlu komitmen dan dukungan lebih dari manajemen sehingga pengguna merasa dengan adanya sistem ini dapat meningkatkan kualitas pelayanan rumah sakit.

Kata Kunci: kepuasan pengguna; pls; resep elektronik

\section{ABSTRACT}

Background: One strategy to reduce medication errors to improve hospital quality is to implementation of electronic prescription. However, in its application, obstacles were found in the interaction between technology and human resources, as well as the management and evaluation of electronic prescription that were not optimal.

Objective: This study aims to determine the relationship between the implementation of electronic prescription on user satisfaction.

Methods: This observational study used the Partial Least Square (PLS) method in processing its data. The sample size was 70 respondents using total sampling. The implementation of electronic prescription, users satisfaction, management support and the work environment were variables.

Results: The results showed that the variables of management support and work environment were related to the implementation of electronic prescription with a level of $\alpha=5 \%$. Also, the variable implementation of electronic prescription is related to user satisfaction with a level of $\alpha=5 \%$.

Conclusion: The implementation of electronic prescription had an on user satisfaction. Thus, evaluation of the electronic prescription implementation is corresponding with expectations and benefits felt by users, nevertheless, it requires more commitment and support form management so that users feel that this system can improve the quality of hospital services.

Keyword: electronic prescribing; user satisfaction; pls 
PENDAHULUAN

Pelayanan farmasi merupakan unit paling berisiko di rumah sakit dalam menunjang mutu pelayanan kesehatan. Tuntutan pasien dan masyarakat mengakibatkan pelayanan farmasi berkembang dari drug oriented menjadi patient oriented untuk meningkatkan kualitas hidup pasien. Hal ini dipengaruhi oleh peningkatan kebutuhan jumlah obat, perkembangan produksi dalam skala besar, inovasi dalam penemuan obat baru, dan timbulnya penyakit baru sehingga pelayanan farmasi perlu meningkatkan kualitas pelayanannya (Kemenkes \& IAI, 2011).

Proses pemberian resep kepada pasien terkadang terjadi kesalahan baik kesalahan dalam diagnosis maupun kesalahan dalam peresepan. Oleh karenanya, pelayanan kesehatan menyadari pentingnya melakukan perubahan untuk menurunkan medication errors, salah satunya dengan pembuatan sistem resep elektronik. Resep elektronik merupakan intervensi dalam meningkatkan mutu pelayanan yang berorientasi pada keselamatan pasien melalui sistem informasi manajemen rumah sakit (SIM RS) yang menghubungkan dokter, apotek, manajer farmasi, dan bagian keuangan. Tujuan dari implementasi resep elektronik antara lain dapat mengurangi kesalahan peresepan, mempercepat permintaan resep ulang, mengurangi pengentrian data, mempercepat waktu tunggu dan meningkatkan efisiensi serta membantu untuk menghemat biaya kesehatan dalam jangka panjang (Porterfield et al., 2014).

Dalam pelaksanaannya masih ada hambatan yaitu biaya pengadaan tinggi, kurangnya dukungan penyedia, privasi pasien berkurang, dan kesalahan sistem. Dampak dari implementasi resep elektronik masih belum jelas, masih ditemukan beberapa kendala terkait interaksi antara teknologi dengan sumber daya manusia, serta belum optimalnya pengelolaan dan evaluasi resep elektronik yang berdampak pada kepuasan pengguna (Ahmed et al., 2016; Donyai et al., 2008; Velo \& Minuz, 2009). Berdasarkan temuan tersebut, untuk memastikan keberhasilan sistem perlu dilakukan evaluasi dengan melihat kepuasan di kalangan pengguna resep elektronik. Tujuan penelitian ini mengetahui hubungan implementasi resep elektronik terhadap kepuasan pengguna yang dapat dijadikan sebagai bahan acuan untuk perbaikan sistem.

\section{METODE}

Jenis penelitian yang digunakan dalam penelitian ini adalah observasional. Sampel penelitian adalah semua dokter dan petugas farmasi (apoteker dan tenaga teknis kefarmasian) berjumlah 70 dengan teknik pengambilan total sanpling, Pengumpulan data menggunakan kuesioner dengan skala likert empat tingkatan. Pengolahan data menggunakan software SmartPLS (Partial Least Square), dengan tiga tahapan yaitu :

1. Model Pengukuran

a. Uji convergent validity, dilihat berdasarkan hasil loading factor dengan nilai $>0,50$. Kriteria pengujian convergent validity dengan average variance extracted (AVE) (Ghozali, 2014).

Rumus AVE

$$
A V E=\frac{\sum \lambda_{i}^{2}}{\sum \lambda_{i}^{2}+\sum_{i} \operatorname{var} \varepsilon_{(i)}}
$$

Dimana adalah loading factor dan var

b. Uji discriminant validity

Membandingkan nilai AVE dengan latent variable correlations.

c. Uji Reliabilitas

Pengukuran reliabilitas variabel menggunakan composite reliability dengan nilai $>0,70$ dan Cronbach's alpha dengan nilai > 0,60 (Ghozali, 2014). 


Rumus Composite Reliability
$\rho c=\frac{\left(\sum \lambda_{i}\right)^{2}}{\left(\sum \lambda_{i}\right)^{2}+\sum_{i} v a r \varepsilon_{(i)}}$
Rumus Cronbach's Alpha
$\alpha=\frac{\sum_{p \neq p^{\prime}} \operatorname{cor}\left(X_{p q}, X_{p^{\prime} q}\right)}{P_{q}+\sum_{p \neq p^{\prime}} \operatorname{cor}\left(X_{p q}, X_{p^{\prime} q}\right)} \times \frac{P_{q}}{P_{q}-1}$
2. Model struktural

Model ini digunakan untuk menggambarkan hubungan kausalitas antar variabel laten. Uji model struktural yang digunakan dalam penelitian ini, yaitu :

a. R-Square (R2) dengan melihat nilai latent variable correlations dengan $\mathrm{R}>$ 0,05. Jika nilai R2 sebesar 0,67 (kuat), 0,33 (moderat), dan 0,19 (lemah) (Ghozali, 2014).

b. Q-square (Q2) untuk menghitung nilai observasi dari hasil model penelitian dan perkiraan paramaternya. Rentang nilai $0<1$, menunjukkan model semakin mendekati angka 1 maka semakin baik (Ghozali, 2014).

Rumus $Q$-square

$$
Q^{2}=1-\left(1-R_{1}^{2}\right)\left(1-R_{2}^{2}\right) \ldots\left(1-R_{p}^{2}\right)
$$

3. Pengujian hipotesis

Statistik uji yang digunakan :

$$
t=\frac{\gamma}{S E(\gamma)}
$$

Kriteria pengujian dengan taraf signifikansi $5 \%$ maka t-statistik $>\mathrm{t}$ tabel atau $p$-value $<\alpha$.

Penelitian ini mengukur masing masing construct dalam model penelitian dengan variabel endogen yaitu kepuasan pengguna, variabel eksogen yaitu dukungan manajemen dan lingkungan kerja, serta variabel laten yaitu implementasi resep elektronik. Setiap variabel memiliki indikator seperti pada variabel dukungan manajemen yaitu komitmen, kemampuan manajemen, perhatian manajemen, dan pengetahuan dalam tingkat pemakaian resep elektronik. Indikator pada variabel lingkungan kerja, yaitu ketersediaan fasilitas, komunikasi, hubungan interorganisasional, kompetisi dan sumber pembiayaan (Sedarmayanti, 2011). Pada variabel implementasi resep elektronik yaitu kualitas data dan informasi, terdiri dari akurat, relevan serta ketepatan waktu. Indikator pada variabel kepuasan pengguna menggunakan teori UTAUT (Unified Theory of Acceptance and Use of The Technology) (Nugraha \& Astuti, 2013; Venkatesh et al., 2003)

Model penelitian pada Gambar 1 menjelaskan hubungan antara variabel eksogen dan endogen, dimana hipotesis penelitiannya, sebagai berikut :

H1 : Ada hubungan dukungan manajemen terhadap implementasi resep elektronik

$\mathrm{H} 2$ : Ada hubungan lingkungan kerja terhadap implementasi resep elektronik

H3 : Ada hubungan implementasi resep elektronik dengan kepuasan pengguna

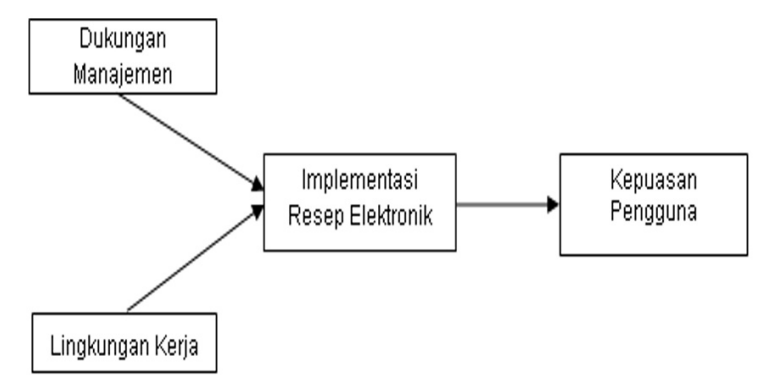

Gambar 1. Model Penelitian

\section{HASIL DAN PEMBAHASAN}

Responden didominasi oleh perempuan 38 orang $(54,30 \%)$ dan laki laki 32 orang $(45,70 \%)$ dengan usia berkisar 30 - 50 tahun $(60,00 \%)$, kurang dari 30 tahun $(14,30 \%)$ dan lebih dari 50 tahun $(25,70 \%)$. Usia responden tergolong dalam usia produktif yang secara teoretis memiliki motivasi tinggi dalam mengikuti perkembangan teknologi informasi, khususnya di bidang kesehatan sehingga dapat meningkatkan perilaku penerimaan aplikasi sistem informasi. Lama kerja sebagian besar pekerja kurang dari 5 tahun (52,86\%) dengan tingkat pendidikan paling banyak adalah dokter spesialis sebanyak 35 orang $(50,00 \%)$. 
Hubungan Implementasi Sistem Resep Elektronik terhadap Kepuasan Pengguna...

1. Evaluasi Model Pengukuran

Hasil penelitian dalam Tabel 1 tidak ada nilai loading factor dibawah 0,50, artinya indikator telah memenuhi convergent validity atau indikator indikator tersebut dikatakan valid.

Tabel 1. Uji Convergent Validity

\begin{tabular}{|c|c|c|}
\hline Variabel & Kode & Outer Loading \\
\hline Dukungan & DM1 & 0,770 \\
\hline \multirow[t]{5}{*}{ Manajemen (DM) } & DM2 & 0,832 \\
\hline & DM4 & 0,797 \\
\hline & DM5 & 0,774 \\
\hline & DM6 & 0,714 \\
\hline & DM7 & 0,806 \\
\hline Implementasi & IMP1 & 0,721 \\
\hline Resep Elektronik & IMP2 & 0,774 \\
\hline \multirow{8}{*}{ (IMP) } & IMP3 & 0,760 \\
\hline & IMP4 & 0,654 \\
\hline & IMP5 & 0,737 \\
\hline & IMP6 & 0,789 \\
\hline & IMP7 & 0,775 \\
\hline & IMP8 & 0,823 \\
\hline & IMP9 & 0,770 \\
\hline & IMP10 & 0,703 \\
\hline Kepuasan & KP1 & 0,775 \\
\hline \multirow[t]{15}{*}{ Pengguna (KP) } & KP2 & 0,734 \\
\hline & KP3 & 0,721 \\
\hline & KP4 & 0,764 \\
\hline & KP5 & 0,674 \\
\hline & KP6 & 0,666 \\
\hline & KP8 & 0,695 \\
\hline & KP9 & 0,731 \\
\hline & KP10 & 0,772 \\
\hline & KP11 & 0,641 \\
\hline & KP12 & 0,831 \\
\hline & KP13 & 0,799 \\
\hline & KP14 & 0,602 \\
\hline & KP15 & 0,751 \\
\hline & KP16 & 0,612 \\
\hline & KP19 & 0,635 \\
\hline Lingkungan Kerja & LK1 & 0,804 \\
\hline \multirow[t]{4}{*}{ (LK) } & LK2 & 0,848 \\
\hline & LK3 & 0,694 \\
\hline & LK4 & 0,874 \\
\hline & LK5 & 0,805 \\
\hline
\end{tabular}

Tabel 2 menunjukkan nilai AVE tidak ada yang kurang dari 0,50, artinya variabel valid dan memenuhi syarat sebagai model penelitian yang baik.
Tabel 2. Nilai Discriminant Validity

\begin{tabular}{ccc}
\hline Variabel & AVE & VAVE \\
\hline IMP & 0,566 & 0,752 \\
DM & 0,613 & 0,783 \\
LK & 0,652 & 0,807 \\
KP & 0,512 & 0,716 \\
\hline
\end{tabular}

Uji reliabilitas pada Tabel 3 terlihat bahwa nilai composite reliability dan nilai cronbach's alpha memenuhi syarat reliabel.

Tabel 3. Nilai Composite Reliability dan Cronbach Alpha

\begin{tabular}{ccc}
\hline Variabel & $\begin{array}{c}\text { Composite } \\
\text { Reliability }\end{array}$ & $\begin{array}{c}\text { Cronbach } \\
\text { Alpha }\end{array}$ \\
\hline IMP & 0,928 & 0,914 \\
DM & 0,905 & 0,874 \\
LK & 0,903 & 0,865 \\
KP & 0,943 & 0,936 \\
\hline
\end{tabular}

2. Evaluasi model struktural

Nilai R2 pada Tabel 4, terlihat bahwa variabel implementasi resep elektronik (IMP) sebesar 0,390 termasuk kategori moderat dan variabel kepuasan pengguna (KP) sebesar 0,768 termasuk kategori baik. Nilai R2 pada kepuasan pengguna menjelaskan bahwa variabel kepuasan pengguna dapat dijelaskan oleh variabel implementasi resep elektronik sebesar $76,8 \%$.

Tabel 4. Nilai R2

\begin{tabular}{lc}
\hline \multicolumn{1}{c}{ Variabel } & $\mathbf{R}^{2}$ \\
\hline $\begin{array}{l}\text { Implementasi Resep } \\
\text { Elektronik (IMP) }\end{array}$ & 0,390 \\
$\begin{array}{l}\text { Kepuasan Pengguna } \\
(\mathrm{KP})\end{array}$ & 0,768 \\
\hline
\end{tabular}

Selanjutnya, hasil R2 dimasukan ke dalam persamaan Q-square, sebagai berikut :

$$
\begin{aligned}
& \mathrm{Q} 2=1-(1-0,390)(1-0,768) \\
& \mathrm{Q} 2=1-(0,610)(0,232) \\
& \mathrm{Q} 2=1-0,14152 \\
& \mathrm{Q} 2=0,85848
\end{aligned}
$$

Berdasarkan perhitungan tersebut, nilai $Q$-square sebesar 0,85848 dimana model penelitian menunjukkan variabel dukungan manajemen, lingkungan kerja, dan implementasi resep elektronik memiliki tingkat prediksi yang baik terhadap kepuasan pengguna. 
3. Pengujian Hipotesis

Untuk mengukur tingkat signifikansi dapat dilihat dari Tabel 5 dimana nilai $\mathrm{t}$ statistik $>\mathrm{t}$ tabel $(\alpha=5 \%$, $\mathrm{t}$-tabel $=1,67)$ melalui proses bootstrapping pada software SmartPLS.

Tabel 5. Nilai Path Coffiecients dan Tstatistik

\begin{tabular}{cccc}
\hline $\begin{array}{c}\text { Diagram } \\
\text { jalur }\end{array}$ & $\begin{array}{c}\text { Original } \\
\text { Sampel }\end{array}$ & T-statistik & Ket \\
\hline $\mathrm{DM} \rightarrow \mathrm{IMP}$ & 0,391 & 2,538 & Signifikan \\
$\mathrm{IMP} \rightarrow \mathrm{KP}$ & 0,528 & 5,292 & Signifikan \\
$\mathrm{LK} \rightarrow \mathrm{IMP}$ & 0,261 & 1,719 & Signifikan \\
\hline
\end{tabular}

Dari Tabel 5, terlihat bahwa hubungan antar dua construct memiliki hubungan yang signifikan (t-statistik > 1,67). Hasil uji kesesuaian model dari indikator terhadap variabel dapat dilihat pada Gambar 2 yang dilengkapi dengan nilai outer loading, nilai $R$-square dan nilai total effect. Output outerloading diperoleh dari PLS Algorithm Report pada software SmartPLS. Pada Gambar 2 menunjukkan indikator tidak ada yang dikeluarkan dari model penelitian karena tidak ada nilai dibawah 0,50 .

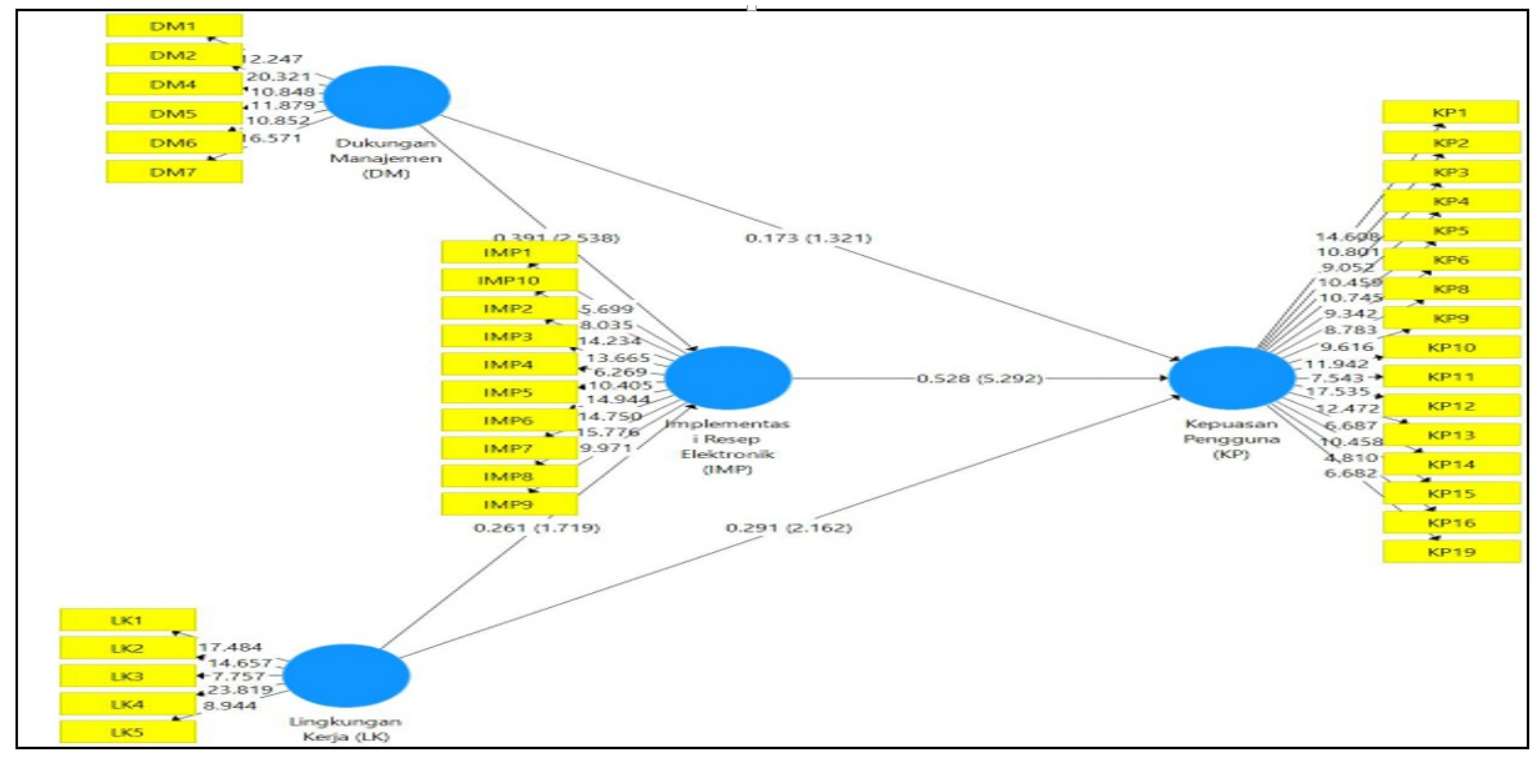

Gambar 2. Keluaran Model Penelitian

Secara keseluruhan hipotesis pada penelitian ini dapat diterima yaitu dengan nilai $\mathrm{t}$ - statistik $>1,67$. Implementasi resep elektronik dapat meningkatkan kualitas pelayanan melalui tiga perspektif, yaitu perspektif organisasi, teknologi dan manusia (Barber et al., 2006). Komponen organisasi meliputi struktur organisasi dan lingkungan kerja. Struktur organisasi menilai dukungan manajemen terhadap keberhasilan implementasi sistem resep elektronik. Dukungan manajemen mempunyai hubungan signifikan terhadap implementasi resep elektronik (t-statistik sebesar 2,538 $\geq 1,67$, hipotesis 1 diterima). Faktor penting dalam mencapai kesuksesan sistem informasi pelayanan pasien adalah dukungan manajemen (Dewi \& Dwirandra, 2013).

Salah satu bentuk komitmen nyata yang diberikan manajemen berupa keterlibatan secara aktif dalam implementasi resep elektronik berupa pembuatan dan pengesahan regulasi implementasi resep elektronik, serta komitmen bersama antar manajemen dengan karyawan dalam memberikan pelayanan prima yang diperlukan untuk mendapatkan kepercayaan masyarakat. Hasil penelitian sesuai dengan penelitian sebelumnya dimana dukungan manajemen memiliki hubungan signifikan terhadap implementasi sistem informasi (Dewi \& Dwirandra, 2013; Rusdi \& Megawati, 2011).

Selain dukungan manajemen, lingkungan kerja juga mempunyai hubungan yang signifikan terhadap implementasi resep elektronik (t-statistik sebesar $1,719 \geq 1,67$, hipotesis 2 diterima). Dalam pengelolaan aktivitas perusahaan, tingkat pemanfaatan dan penerapan

https://jurnal.ugm.ac.id/jkesvo Published online August 31, 2020 
teknologi informasi sangat dibutuhkan, dalam hal ini untuk meningkatkan pelayanan resep kepada pasien (Lee \& Grover, 1999). Faktor lingkungan kerja dalam penelitian ini berupa tersedianya infrastruktur yang memadai seperti kebutuhan hardware dan software sudah terpenuhi di masing - masing klinik, kemampuan petugas SIM RS dalam pemeliharaan sistem, serta adanya sumber pembiayaan sebagai dukungan dalam pemeliharaan fasilitas rumah sakit.

Komponen teknologi mengukur kualitas sistem, kualitas layanan serta kualitas data dan informasi. Pada penelitian ini indikator untuk mengukur implementasi sistem resep elektronik adalah relevansi, akurasi dan ketepatan waktu. Dalam hal ini, komponen teknologi adalah implementasi sistem resep elektronik mempunyai hubungan signifikan terhadap kepuasan pengguna (t-statistik sebesar 5,292 $\geq 1,67$, hipotesis 3 diterima). Sejalan dengan penelitian sebelumnya, bahwa karakteristik pengguna memengaruhi kepuasan pengguna yang berhubungan dengan manfaat dan sikap pengguna terhadap sistem resep elektronik. Semakin baik implementasi resep elektronik maka semakin tinggi tingkat kepuasan penggunanya. Oleh karena itu, kepuasan pengguna memberikan manfaat terhadap pengguna dan organisasi yang dapat meningkatkan kepercayaan dan loyalitas pelanggan (Machmud, 2018; Widiastuti \& Dwiprahasto, 2014).

Pengguna resep elektronik yaitu dokter dan petugas farmasi memberikan persepsi yang baik terhadap implementasi resep elektronik, antara lain informasi obat yang ada di dalam resep elektronik relevan sehingga dapat mendukung dalam pengambilan keputusan, implementasi resep elektronik akurat sehingga dapat mengeliminasi kesalahan dalam penulisan resep, serta kemudahan dalam pembacaan resep sehingga dapat membantu pelayanan pasien dengan memberikan informasi yang berkualitas (Samitsch, 2015).

Keberhasilan implementasi resep elektronik mampu meningkatkan mutu pelayanan rumah sakit dengan mempercepat pelayanan di instalasi farmasi, antara lain memperpendek waktu tunggu pasien, rumah sakit dapat melakukan efisiensi di era Jaminan Kesehatan Nasional (JKN), mempersingkat alur pelayanan farmasi.

\section{PENUTUP}

Hasil dari penelitian ini menyimpulkan bahwa ada hubungan signifikan antara dukungan manajemen dan lingkungan kerja terhadap implementasi sistem resep elektronik dilihat dari sikap pengguna dalam merespon teknologi sistem resep elektronik, serta implementasi resep elektronik terhadap kepuasan pegguna. Dengan demikian, implementasi resep elektronik sudah sesuai dengan harapan dan manfaat yang dirasakan pengguna, sehingga dapat memberikan pelayanan paripurna yang berorientasi terhadap keselamatan pasien. Diharapkan ada penelitian lebih lanjut untuk mengevaluasi keberhasilan implementasi resep elektronik yang berorientasi pada keselamatan pasien.

\section{DAFTAR PUSTAKA}

Ahmed, Z., Barber, N., Jani, Y., Garfield, S., \& Franklin, B. D. (2016). Economic impact of electronic prescribing in the hospital setting: A systematic review. International Journal of Medical Informatics, 88, 1-7. https://doi.org/ 10.1016/j.ijmedinf.2015.11.008

Barber, N., Franklin, B. D., Cornford, T., Klecun, E., \& Savage, I. (2006). Safer, Faster, Better? Evaluating Electronic Prescribing. In Report to The Patient Safety Research Programme. http:// wwwlive.who.int/entity/patientsafety/ information_centre/reports/ PS019_Barber_Final_report.pdf 
Hubungan Implementasi Sistem Resep Elektronik terhadap Kepuasan Pengguna...

Dewi, S., \& Dwirandra, A. (2013). Pengaruh Dukungan Manajemen Puncak, Kualitas Sistem, Kualitas Informasi, Pengguna Aktual dan Kepuasan Pengguna Terhadap Implementasi Sistem Informasi Keuangan Daerah di Kota Denpasar. E-Jurnal Akuntansi, 4(1), 196-214.

Donyai, P., O'Grady, K., Jacklin, A., Barber, N., \& Franklin, B. D. (2008). The effects of electronic prescribing on the quality of prescribing. British Journal of Clinical Pharmacology, 65(2), 230-237. https://doi.org/10.1111/j. 1365-2125.2007.02995.x

Ghozali, I. (2014). Structural Equation Modeling, Metode Alternatif dengan Partial Least Square (PLS). (4th ed.). Badan Penerbit Universitas Diponegoro.

Kementerian Kesehatan, \& Ikatan Apoteker Indonesia. (2011). Pedoman Cara Pelayanan Kefarmasian yang Baik (CPFB) (A. Mashuda (ed.)). http:// iaijatim.id/wp-content/uploads/

2019/11/Panduan-Pelayanan-

Kefarmasian-GPP-praktikapoteker.pdf

Lee, C. C., \& Grover, V. (1999). Exploring Mediation between Environmental and Structural Attributes: The Penetration of Communication Technologies in Manufacturing Organizations. Journal of Management Information Systems, 16(3), 187-217. https://doi.org/

10.1080/07421222.1999.11518261

Machmud, R. (2018). Kepuasan Penggunaan Sistem Informasi. Ideas Publishing.

Nugraha, H. A., \& Astuti, Y. W. (2013). Analisis Penerapan Sistem Informasi Manajemen Keuangan Daerah (SIMDA Keuangan) dalam Pengolahan Data Keuangan Pada Organisasi Pemerintah Daerah (Studi Kasus Pada Dinas Kesehatan Kabupaten Nganjuk). Jurnal Akuntansi Aktual, 2(1), 25-33. http:// journal.um.ac.id/index.php/jaa/article/ view/10444/5119

Porterfield, A., Engelbert, K., \& Coustasse, A. (2014). Electronic prescribing: improving the efficiency and accuracy of prescribing in the ambulatory care setting. Perspectives in Health Information Management / AHIMA, American Health Information Management Association, 11, 1-24. https://www.ncbi.nlm.nih.gov/pmc/ articles/PMC3995494/pdf/phim00110001g.pdf

Rusdi, D., \& Megawati, N. (2011). Analisis Faktor - Faktor yang Mempengaruhi Kinerja Sistem Informasi Akuntansi (SIA). Majalah Ilmiah Sultan Agung, 49(125). http://jurnal.unissula.ac.id/ index.php/majalahilmiahsultanagung/ article/view/44

Samitsch, C. (2015). Data Quality and its Impacts on Decision-Making. Springer Fachmedien Wiesbaden. https:// doi.org/10.1007/978-3-658-08200-0

Sedarmayanti. (2011). Membangun dan Mengembangkan Kepemimpinan serta Meningkatkan Kinerja untuk Meraih Keberhasilan (1st ed.). PT. Refika Aditama.

Velo, G. P., \& Minuz, P. (2009). Medication Errors: Prescribing Faults and Prescription Errors. British Journal of Clinical Pharmacology, 67(6), 624-628. https://doi.org/10.1111/j.13652125.2009.03425.x

Venkatesh, Morris, Davis, \& Davis. (2003). User Acceptance of Information Technology: Toward a Unified View. MIS Quarterly, 27(3), 425. https:// doi.org/10.2307/30036540

Widiastuti, M. S., \& Dwiprahasto, I. (2014). Peran Resep Elektronik dalam Meningkatkan Medication Safety pada Proses Peresepan. Jurnal Manajemen Pelayanan Kesehatan, 17(1), 30-36. https://media.neliti.com/media/ publications/114769-ID-peran-resepelektronik-dalam-meningkatka.pdf 